\title{
Co-pay cards in Canada: Improving choice or institutionalizing bribes?
}

\author{
Marc-André Gagnon PhD
}

n Cite as: CMAJ 2019 November 11;191:E1235-6. doi: 10.1503/cmaj.191447

See related article at www.cmaj.ca/lookup/doi/10.1503/cmaj.190098

B etween 2010 and 2015, many patents for blockbuster drugs expired, and pharmaceutical companies were faced with competition from the makers of generic versions ("generics"). It was called the "patent cliff." ${ }^{1}$ To preserve their market share, producers of brand-name drugs introduced loyalty cards as a critical marketing strategy to promote drugs that were no longer under patent, like Lipitor, Crestor and Nexium. Also called co-pay cards (CPCs), these loyalty cards lower patients' copay amount for a brand-name product to the level it would have been if they had purchased a generic. ${ }^{2}$ Essentially, pharmaceutical companies act as a second insurance payer through the cards so that patients are free to choose between a (more expensive) brand-name drug or a lower-priced generic without having to pay more out of pocket for the former. In Canada, 2 loyalty card programs dominate the market, covering about 150 products. The introduction of mandatory generic substitution was intended to entirely mitigate the negative effects that CPCs could have on payers' costs. However, the findings of a linked study by Law and colleagues $^{3}$ suggest that this is not entirely the situation.

Serious concerns related to CPCS have been highlighted previously. ${ }^{4,5}$ First, use of the cards means that confidential clinical data of individual patients are provided to drug companies. Second, concerns have been raised about the costs and financial incentives associated with CPCs. To illustrate this, let's assume that a drug costs $\$ 100$ for the brand-name version, $\$ 20$ for the generic version; the dispensing fee is $\$ 10$; the pharmacy margin is $10 \%$; and the insured patient pays a co-pay rate of $20 \%$. Public and private drug plans usually use cost-sharing mechanisms like co-pays to steer the insured toward the most cost-efficient choice of medications. ${ }^{6}$

Box 1 presents some typical payment structures for a prescription based on different scenarios. Scenarios A and B consider the situation where an individual without a CPC chooses between a generic or brand-name drug. Because of the cost-sharing mechanism, the insured would normally pay less out of pocket for a generic version of the pill (\$6.40) than for the brand-name product (\$24). However, if the insured uses a CPC to buy a brand-name product when a lowerpriced generic is available, as in scenario $C$, the pharmaceutical company through the CPC will pay the difference in the $20 \%$ co-pay rate

\section{KEY POINTS}

- Loyalty cards were drug companies' response to the "patent cliff" of the early 2010s, to encourage patients to continue using brand-name drugs as cheaper generics became available.

- Also known as co-pay cards, these brand loyalty products have been shown to allow drug companies access to patients' confidential clinical information and to increase prescriptions stipulating that brand-name drugs must be supplied.

- Co-pay cards may also increase drug costs for payers by increasing the insured's premiums, although the introduction of mandatory generic substitution was intended to mitigate this effect.

- New evidence suggests that the purveyors of loyalty cards may even financially incentivize patients to push for brand-name drugs by ensuring that the patient's co-pay is less for a brandname than a generic drug.

Box 1: Typical payment structures in \$ for a prescription based on different drug and CPC scenarios

\begin{tabular}{|c|c|c|c|c|}
\hline Scenario & Insurer & Insured & CPC & $\begin{array}{l}\text { Total } \\
\text { cost }\end{array}$ \\
\hline A. Generic & 25.60 & 6.40 & 0 & 32.00 \\
\hline B. Brand-name without CPC & 96.00 & 24.00 & 0 & 120.00 \\
\hline C. Brand-name with CPC & 96.00 & 6.40 & 17.60 & 120.00 \\
\hline $\begin{array}{l}\text { D. Brand-name with CPC } \\
\text { and mandatory generic } \\
\text { substitution }\end{array}$ & 25.60 & 6.40 & 88.00 & 120.00 \\
\hline $\begin{array}{l}\text { E. Average cost within } \\
\text { public plans based on } \\
\text { results of Law et al. }{ }^{3}\end{array}$ & 25.93 & 10.93 & 83.14 & 120.00 \\
\hline $\begin{array}{l}\text { F. Average cost within } \\
\text { private plans based on } \\
\text { results of Law et al. }{ }^{3}\end{array}$ & 37.38 & 6.27 & 76.35 & 120.00 \\
\hline
\end{tabular}

Note: $\mathrm{CPC}=$ co-pay card.

Source: Calculations by the author, based on cost of $\$ 100$ for brand-name version; $\$ 20$ for generic version; $\$ 10$ dispensing fee; $10 \%$ pharmacy margin; and $20 \%$ co-pay for insured patient. 
between the brand-name product and the generic. Although the insured may have the impression that the CPC saves them money, the drug plan pays $\$ 96$ for the brand-name drug instead of $\$ 25.60$ for the generic. If the insured is on a private plan for which premiums are determined based on last year's total expenditures, savings incurred over the counter when using a CPC are not true savings, as the insured's premiums will increase.

The best way for drug plans to protect themselves against higher expenditures for a similar therapeutic treatment is to introduce generic substitution; in this case, the drug plan will reimburse only for the equivalent of the generic. However, physicians can circumvent generic substitution easily by writing "no substitution" on the prescription, in which case the drug plan must pay for the brand-name product. ${ }^{7}$ When CCPs were introduced, pharmacies saw a substantial increase in prescriptions stipulating "no substitution" (Jason Kennedy, Data from 2012 TELUS Health Book of Business, Presentation for Telus Health: unpublished data, 2013); to protect themselves against this trend, all public and most private plans introduced "mandatory generic substitution," ${ }^{8}$ where the drug plan pays only the equivalent cost of the generic even if "no substitution" is written on the prescription. Alternatively, the plans require medical justifications before agreeing to reimburse for the brand-name product, as shown in Box 1, scenario D.

However, the findings of the linked research ${ }^{3}$ show that, while costs seem to have been contained for public plans (Box 1, scenario E), there is still cause for concern for private plans (scenario F) because the cost for the insurer goes from $\$ 25.60$ to $\$ 37.38$ - an increase of $46 \%$ - for a product that does not provide any additional therapeutic benefit.

The most surprising finding of the linked research, however, is that use of a CPC was found to be associated with a decrease in the average cost paid by the insured when they select the more expensive treatment. ${ }^{3} \mathrm{~A}$ more granular analysis of Law and colleagues' work shows that, while CPCs cover only half of the co-pay difference for some drugs, such as Effexor, Norvasc or Lipitor, they cover more than the co-pay difference for others, such as Concerta, Nexium, Wellbutrin and Suboxone. This is concerning. These findings imply that drug companies, sometimes, appear to be paying patients to select the more expensive drug option.

Consider this hypothetical analogy, which could not occur in Canada but might, arguably, be possible in health systems where services are not paid for out of the public purse. Imagine if a user fee of $\$ 20$ existed for every visit to a hospital's emergency department, but to attract more patients and collect more fees for service from insurers, hospitals would pay that user fee and give the patient an additional $\$ 10$ to increase the number of visits. We would probably all agree that, in such a case, the hospital could be perceived to be increasing revenues in a manner that artificially wastes resources and inflates costs. Yet, the situation in Canada in which people covered under private drug plans use CPCs to purchase some brand-name drugs might not be so very different. Under the guise of reducing costs and increasing choice for patients, CPCs may be doing much more.

As noted previously, CPCs potentially allow the transfer of confidential clinical information of individual patients to drug companies. In addition, as previously reported, ${ }^{4} \mathrm{CPC}$ may influence health care professionals to promote the message that brand-name products are better (by complying with patient requests to specify "no substitution" on prescriptions). They likely also waste resources, increase costs for patients (by increasing their insurance premiums) and may even incentivize patients to push for brand-name drugs through a mechanism that many might consider to border on institutionalized bribery.

\section{References}

1. Harrison C. Patent watch: The patent cliff steepens. Nat Rev Drug Discov 2011; 10:12-3.

2. Prémont $\mathrm{M}-\mathrm{C}$, Gagnon $\mathrm{M}-\mathrm{A}$. Three types of brand name loyalty strategies set up by drug manufacturers [article in French]. Healthc Policy 2014;10:79-89.

3. Law MR, Chan FKI, Harrison M, et al. Impact of brand drug discount cards on private insurer, government and patient expenditures. CMAJ 2019;191: E1237-41.

4. Grande D. The cost of drug coupons. JAMA 2012;307:2375-6.

5. Chauncey D, Mullins CD, Tran BV, et al. Medication access through patient assistance programs. Am J Health Syst Pharm 2006;63:1254-9.

6. Gagnon M-A. The role and impact of cost-sharing mechanisms for prescription drug coverage. CMAJ 2017;189:E680-1.

7. MacDonald K. Freedom of choice may be coming to an end in drug plans. Benefits Can; 2016.

8. Mensch L. 2019 Drug Data Trends and National Benchmarks Report. Montréal: Telus Health; 2019.

Competing interests: Marc-André Gagnon has no financial relationships with commercial interests. In the last 5 years, he has consulted for Health Canada and Prescrire International.

This article was solicited and has not been peer reviewed.

Affiliation: School of Public Policy and Administration, Carleton University, Ottawa, Ont.

Funding: The author has received funding from Health Canada for research on cost-sharing mechanisms.

Correspondence to: Marc-André Gagnon, ma.gagnon@carleton.ca 